\title{
BMJ Open Quality Supplementing hand washing with proper use of alcoholic hand rub in a special neonatal care unit in a large academic public health institute at Jabalpur, Madhya Pradesh, India
}

\author{
Mahtab Singh, ${ }^{1}$ Avyact Agrawal, ${ }^{2}$ Deepti Sisodia, ${ }^{2}$ Pardeep Kumar Kasar, ${ }^{3}$ \\ Arvinder Kaur, ${ }^{4}$ Vikram Datta (D) , ${ }^{5,6}$ Ravi Shankar Savanna, ${ }^{7}$ Manish Singh, ${ }^{8}$ \\ Nigel Livesley ${ }^{9}$
}

To cite: Singh M, Agrawal A, Sisodia D, et al. Supplementing hand washing with proper use of alcoholic hand rub in a special neonatal care unit in a large academic public health institute at Jabalpur, Madhya Pradesh, India. BMJ Open Quality 2021;10:e001131. doi:10.1136/ bmjoq-2020-001131

Received 25 August 2020 Accepted 25 October 2021

Check for updates

(c) Author(s) (or their employer(s)) 2021. Re-use permitted under CC BY-NC. No commercial re-use. See rights and permissions. Published by BMJ.

For numbered affiliations see end of article.

Correspondence to Dr Mahtab Singh; drmahtab2013@gmail.com

\section{ABSTRACT}

Objective The purpose was to increase use of alcoholic hand rub (AHR) in specialised newborn care unit (SNCU) to improve hand hygiene in order to reduce neonatal sepsis and mortality at Netaji Subhash Chandra Bose Medical College and Hospital, Jabalpur.

Design A prospective interventional and observational study.

Methodology We formed a quality improvement (QI) team in our SNCU consisting of doctors, nurses, auxiliary staff and parents (a floating member) to improve proper use of AHR. To identify the barriers to the problem, we used fishbone analysis tool. The barriers which were not allowing the health providers to use AHR properly identified were amount of AHR in millilitres to be used per day per baby, how much and when the amount of AHR to be indented from the main store and what is the proper site to place the bottle. We used plan-do-study-act cycles to test and adapt solutions to these problems. Within 5-6 weeks of starting our project, AHR use increased from $44 \mathrm{~mL}$ to $92 \mathrm{~mL}$ per baby per day and this is sustained around $100 \mathrm{~mL}$ per baby per day for over 2 years now.

Results Significant decrease in neonatal mortality was observed (reduced from median of 41.0 between August 2016 and April 2018 to 24.0 between May 2018 and December 2019). The neonates discharged alive improved from 41.2 to 52.3 as a median percentage value. The percentage of babies who were referred out and went Left Against Medical Advice (LAMA) deceased too.

Conclusion Multiple factors can lead to neonatal deaths, but the important factors are always contextual to facilities. QI methodology provides health workers with the skills to identify the major factors contributing to mortality and develop strategies to deal with them. Improving processes of care can lead to improved hand hygiene and saves lives.

\section{BACKGROUND}

Neonatal sepsis is a major cause of newborn mortality. Predisposing causes include prolonged special newborn care unit (SNCU) stay, invasive procedures, over and irrational use of broad-spectrum antibiotics and transmission of infection through hands of care providers. ${ }^{1}$ Hand hygiene is an important factor and, if taken care of, can reduce neonatal sepsis in SNCUs and reduce mortality. ${ }^{2}$ Spread of infection through contaminated hands of health providers and care givers is a very common phenomenon throughout the world, it is more so in low-income and middle-income countries (LMICs) like India. ${ }^{3}$ The problem of hand hygiene further favoured by resource constraint settings with overcrowded SNCUs with patients in almost all over India and Madhya Pradesh.

The sustainable development goals have committed to end preventable deaths of newborns and children under 5 years of age (under 5 mortality), with all countries aiming to reduce neonatal mortality to at least as low as 12 per 1000 live births and under 5 mortality to at least as low as 25 per 1000 live births. ${ }^{4}$ We all know what services to be given to newborns to reduce these deaths, but often we do not provide those services when they are needed. The early initiation of breast feeding in India is $44.6 \%$, exclusive breast feeding is $64.9 \%$ and postnatal health visits for babies only $33.6 \%$ in spite of $78.9 \%$ of deliveries happening at the institutions. ${ }^{5}$

The present level of Infant Mortality Rate (IMR) in India (33 infant deaths per 1000 live births) for the year 2017 is about one-fourth as compared with 1971 (129 infant deaths per 1000 live births). In the last 10 years, IMR has witnessed a decline of about $36.7 \%$ in rural areas and about $36 \%$ in urban areas. ${ }^{4}$

Staff compliance with hand hygiene protocols in neonatal intensive care units (NICUs) is highly important to limit the 
spread of pathogens by the hands of healthcare workers and thus to prevent nosocomial infections. ${ }^{6}$ Incidences of bloodstream infections in infants admitted to NICUs currently range from $12 \%$ to $53 \%{ }^{7}$ There is evidence that improved hand hygiene in NICU settings results in infection reduction. ${ }^{8}$

Netaji Subhash Chandra Bose Medical College and Hospital is a regional tertiary care centre catering surrounding districts of Jabalpur and Rewa division in Madhya Pradesh. This academic health institute caters to around 2500 deliveries yearly and nearly 200 admissions in SNCU on monthly basis. This is a 30 bedded nursery with 4 staff nurses and 6 Post Gratduate (PGs) students posted for providing care in each shift. The monthly average bed occupancy rate is around $150 \%$. Maximum patients admitted to SNCU come from the poor community of Jabalpur and nearby districts. Jabalpur and Rewa region in Madhya Pradesh are agrarian regions and depends on agriculture for their income. We discussed that antibiotic usage was very high (given to all admitted patients) and we have high mortality rates and, hence, our team decided to work on hand hygiene in the unit in order to reduce neonatal sepsis and mortality thereof. The hand hygiene involves so many processes and is a complex issue itself. All the care providers used to wash their hands before entering the SNCU every time but AHR was not being used every time before touching the babies from one bed to other bed. Considering hand hygiene a major contributor for sepsis, we decided to improve this because we thought it was completely under our control and easy to fix. The purpose of this report is to describe how the team used QI methods to solve this problem..$^{9} 10$

\section{BASELINE MEASUREMENT}

We did not have a baseline value for the AHR volume used per baby per day. So, we did a small plan-do-studyact (PDSA) cycle to know the baseline volume used per baby per day. Amount of AHR used was measured for 3 beds in the SNCU for consecutive 3 days and average amount calculated per baby per day which came out to be $44 \mathrm{~mL}$ per baby per day. A 500 -millilitre bottle full with AHR was placed at these beds and the next day after 24 hours the bottle was filled again with a measure and the amount needed to refill was taken as the amount used for that baby.

We calculated how much AHR we should be using for each baby by calculating the number of contacts per day and how much AHR was needed for each contact. Resident doctors were touching an average of 14 times per baby in 24 hours and nurses were touching an average of 25 times per baby in 24 hours. Each push on the AHR dispenser released $1.6 \mathrm{~mL}$ of AHR. The team considered that two pushes $(3.2 \mathrm{~mL})$ provided enough AHR for good hygiene. We, therefore, calculated that good hygiene would require $125 \mathrm{~mL}$ per baby per day. We agreed to $100 \mathrm{~mL}$ per baby per day as sufficient volume of AHR for good hygiene.
The team started documenting AHR usages per baby per day for each bed used for calculation of baseline volume of AHR in a register with random checking from other beds also. Whenever these beds have more than one baby, the average was calculated accordingly. In case of non-occupancy of any of these beds, adjacent bed was included in the study group. The other data related to mortality, Left Against Medical Advice (LAMA) and referral were taken from the SNCU software used in the facility.

\section{DESIGN}

In August 2018, we realised that most of the health staff and care givers do not use AHR to sanitise their hands before touching the neonates every time from one to the other bed. Staff in the SNCU decided to use WHO point-of-care Quality Improvement Model ${ }^{11}$ 12 to solve this problem. We formed a team consisting of consultant, senior resident, postgraduate students, nursing staff and aayas (nursing assistants) posted at SNCU. We also included the parents and attendants as floating members in our team. This team was led by the neonatologist in charge of the SNCU and was supported by external advisors from Nationwide Quality Of Care Network (NQOCN), an organisation working on in India, who provided guidance on using QI methods.

The team set an aim to increase hand hygiene compliance through increased use of AHR from current $44 \mathrm{~mL}$ per baby per day to $100 \mathrm{~mL}$ per baby per day within 2 months. Our goal was to reduce mortality in babies in our SNCU through this approach. We then used the fishbone diagram to identify various factors contributing to improper use of AHR. Through this analysis, we identified a number of problems that could potentially contribute to non-compliance to AHR uses, including stakeholders awareness regarding use of hand rub and its effects, what is right place to put the bottle of AHR and how many bottles and when to indent from the main store of the hospital. The team used PDSA cycles to test various change ideas and adapt to possible solutions to these identified contributing factors. We tested the change ideas with very small samples. The team met weekly to discuss what the team was learning from the various tests and review the data on the volume of AHR used per baby per day. NQOCN coaches visited the team once in a month for a period of 9 months.

We collected data on average volume used per baby per day and analysed it on run charts. For AHR volume data, the first baseline median was calculated using data points from 11 September 2018 to 18 September 2018. We recalculated the median whenever we observed a shift in the data using the criteria used to define a shift (shifts here are done with looking for runs of 9 or more points). ${ }^{13} \mathrm{We}$ also collected data on SNCU mortality (this included the mortality of labour room as all the babies were declared 
dead in SNCU only, even still births) from the SNCU software being used by facility. As balance indicators, we also collected data on LAMA and referral out neonates form SNCU software. These data were plotted on time series chart to see the impact of better hand hygiene compliance.

\section{What we did}

We started with the neonatologist in charge educating all staff about hand hygiene the first week of September 2018. We also posted educational poster on AHR use at the gate of SNCU on 11 September 2018. During the QI team meeting, we found that the AHR was out of stock and people forgot to rub their hands as they did not see the AHR bottle to remind them for rub their hands. We invited the storekeeper and involved him in the QI team to change the indenting process to avoid stock out in the future. We placed the AHR bottle on top of the baby warmer trolley, where it was easily visible at the time anybody approached the bed. The main bottleneck in the indenting system found was that in the department there was no robust system of indenting based on scientific evidences of supply chain management. The storekeeper explained the concept of buffer stock and calculating when to raise the indent based on their actual stock in hand. He also improved his own system of placing orders to the suppliers based on the new demands from the SNCU. He advised the team to raise an indent when they have left with the $50 \%$ of the stock out of 3 months of total requirements in the department. This 3-month time was also calculated based on the time taken for the supplier to supply the order from when it was placed.

The team discussed further and found that it was very important to orient health providers on a regular basis about the use and benefit of the use of AHR. A video was made by the neonatologist in charge and was shared with all the health providers through WhatsApp on a weekly basis. During one team discussion, it was found that the attendants (parents and relatives) and ward aayas were not able to understand what the AHR was. So, the orientation of aayas and attendants was done by doctors to explain AHR as neela pani (blue-coloured water) and later on aayas continued to orient the new attendants on a regular basis.

No major expenses were involved in this project. No additional staffs were recruited, no major equipment was purchased and no construction was done in the existing hospital building. The focus instead was on changing the processes of care to make it easier for staff and other care providers to do things that were stopping them to use AHR. For details about PDSA cycles done, refer table $1 .^{9}$

Patient involvement: no patients were involved in this study because the main focus of the study was to improve a routine clinical process in a hospital setting. Likewise, no patients were involved in the development of the research questions, outcome measures, recruitment and the conduct of the study. The results were disseminated through experience sharing workshops to facility teams, funding partner and governmental agencies.

\section{RESULTS}

From the baseline average volume of $44 \mathrm{~mL}$, it increased to a median of $57.5 \mathrm{~mL}$ per baby per day with the first change idea. Then suddenly, there was stock out of AHR and it dropped to 0 for 18 days. After getting the supply right and changing the place of AHR bottle, the use increased to a median of $76 \mathrm{~mL}$ and subsequently corresponding to other changes the use increased to 90-97.15 mL per baby per day by the end of November 2018 (figure 1). Since then, the amount is consistent and sustained at around $100 \mathrm{~mL}$ per baby per day.

Our data of more than a year on sustenance of use of AHR at a level very close to what the team has planned, itself speaks about the sustainability of changes done. We support the sustainability because we worked on the system changes rather than on people's behaviour by educating them. For example, the AHR bottle was placed at a place where it was not readily visible whenever a care provider approached to provide care. So, we decided to place the bottle of AHR on the neonatal bed at a place where it was readily visible and served as a reminder for the healthcare provider. The space was fixed for the AHR bottle to be placed and now that has become a norm and part of the system. The team used to face the frequent stock out of AHR in the department and the team decided to involve the storekeeper to help the team. The storekeeper was invited to be a part of the QI team and as an expert he helped the team to understand concept of buffer stock and improved the system of raising their indent (team sets a benchmark to raise the indent when they have left with AHR sufficient for 3 months) for the AHR so that there was no stock out in future. Other strategies which are being used at our facility to keep the sustainability of changes done were; all the newly joined health providers are being imparted training or knowledge about all the process and system changes at the time of their joining. The department has a WhatsApp group, which is used as a platform to send the reminder messages/videos and to gather the feedback.

The discharged alive, mortality data were also plotted on run charts to see any changes over time. Although a decreasing trend in neonatal mortality at our facility could be seen from May 2018 onwards which we believe was because of change of leadership. New in-charge joined in SNCU and brought some changes in terms of antibiotic uses and some infrastructural changes like making all air conditioners working, earlier all were not functional. But the mortality, LAMA and referral started decreasing December 2019 onward, which can be because of the better hand hygiene. The proportion of babies discharged alive has increased from 41.2 baseline median between August 2016 and May 2018 to 52.3 baseline median between June 2018 and December 2019. 
Table 1 The team did a number of PDSA cycles to calculate the baseline, to know optimum volume for one complete hand wash, volume to be used per baby per day and many to test changes identified to increase average volume used

\begin{tabular}{|c|c|c|c|c|}
\hline & Plan & Do & Study & Act \\
\hline $\begin{array}{l}\text { PDSA cycle 2: to } \\
\text { know the optimum } \\
\text { volume of AHR to rub } \\
\text { both hands }\end{array}$ & $\begin{array}{l}\text { One PG student will take the } \\
\text { puffs from bottle starting with } \\
\text { one puff and rub his hands } \\
\text { and will tell if the volume was } \\
\text { optimum }\end{array}$ & $\begin{array}{l}\text { The PG student did as } \\
\text { planned }\end{array}$ & $\begin{array}{l}\text { The two puffs were } \\
\text { found to be optimum } \\
\text { to rub both hands } \\
\text { completely }\end{array}$ & $\begin{array}{l}\text { Team decided to take two } \\
\text { puffs every time to rub the } \\
\text { hands }\end{array}$ \\
\hline $\begin{array}{l}\text { PDSA cycle } 3 \text { : to } \\
\text { know the average } \\
\text { volume to be used } \\
\text { daily per baby }\end{array}$ & $\begin{array}{l}\text { Volume of two puffs will be } \\
\text { measured using a } 5 \text {-millilitre } \\
\text { syringe and all the service } \\
\text { providers will count number of } \\
\text { times they touched a baby for } \\
3 \text { days }\end{array}$ & $\begin{array}{l}\text { All the doctors, } \\
\text { nurses, aayas and } \\
\text { parents did as } \\
\text { planned }\end{array}$ & $\begin{array}{l}\text { The average number } \\
\text { of times the baby was } \\
\text { touched by all was } \\
\text { calculated and multiplied } \\
\text { by the volume of two } \\
\text { puffs }\end{array}$ & $\begin{array}{l}\text { Average volume } \\
\text { was calculated by } \\
3.2 \times 35=112 \text { but benchmark } \\
\text { was set at } 100 \mathrm{~mL} \text { per day } \\
\text { per baby }\end{array}$ \\
\hline $\begin{array}{l}\text { PDSA cycle } 5 \text { : } \\
\text { storekeeper was } \\
\text { invited as a member } \\
\text { in the team to train } \\
\text { staff about the } \\
\text { indenting process } \\
\text { and putting bottle at a } \\
\text { visible site }\end{array}$ & $\begin{array}{l}\text { The storekeeper will be called } \\
\text { in the QI meeting and AHR } \\
\text { bottle will be placed on the } \\
\text { neonatal bed }\end{array}$ & $\begin{array}{l}\text { The storekeeper } \\
\text { attended the QI } \\
\text { meeting and trained } \\
\text { the staff on improving } \\
\text { the indenting process } \\
\text { and AHR bottle was } \\
\text { placed on the bed } \\
\text { where it was readily } \\
\text { visible }\end{array}$ & $\begin{array}{l}\text { The indenting of AHR } \\
\text { process was changed } \\
\text { based on buffer stock } \\
\text { and utilisation }\end{array}$ & $\begin{array}{l}\text { The AHR bottle placed on } \\
\text { the top of baby warmer } \\
\text { bottle served as a reminder } \\
\text { to health providers and the } \\
\text { revised intending process } \\
\text { was adopted. The average } \\
\text { volume used increased to a } \\
\text { median of } 76 \mathrm{~mL}\end{array}$ \\
\hline $\begin{array}{l}\text { PDSA cycle 7: } \\
\text { introduced blue- } \\
\text { coloured water term } \\
\text { for aayas }\end{array}$ & $\begin{array}{l}\text { The PG students will orient } \\
\text { all aayas and parents using } \\
\text { the term neela pani instead } \\
\text { of AHR during orientation } \\
\text { sessions }\end{array}$ & Done as planned & $\begin{array}{l}\text { The aayas and parents } \\
\text { were more comfortable } \\
\text { to understand it and } \\
\text { the average volume } \\
\text { increased to } 97.15 \mathrm{~mL}\end{array}$ & The idea was adopted \\
\hline
\end{tabular}

AHR, alcoholic hand rub; PDSA, plan-do-study-act; PG, postgraduate; QI, quality improvement; SNCU, specialised newborn care unit.

The mortality reduced from a median of 41.0 between August 2016 and April 2018 to 24.0 between June 2018 and December 2019, which is $58.5 \%$ decline in the neonatal mortality in our SNCU. To support our belief that initial decrease in mortality was because of change of leadership, we observed an increase in mortality from August 2019 to December 2019 when again there was change of leadership in the month of July 2019 onward (figure 2). The earlier SNCU I/C (in-charge) became the head of the paediatrics department and the other person in line was made the $\mathrm{I} / \mathrm{C}$ of SNCU and due to this there were some changes in the system at SNCU in terms of less monitoring of the improved process. To resolve this leadership issue, the head of the paediatrics department (earlier SNCU I/C) made the monitoring of AHR use improvement work an agenda point of the weekly departmental review meeting.

\section{LESSONS AND LIMITATION}

We successfully improved the proper use of AHR using QI methods and were able to improve the proportion of babies discharged alive. This was the first time our team used QI approaches in our institute. We started by motivation of our staff through training and general talks to improve on use of AHR but we did not see any 


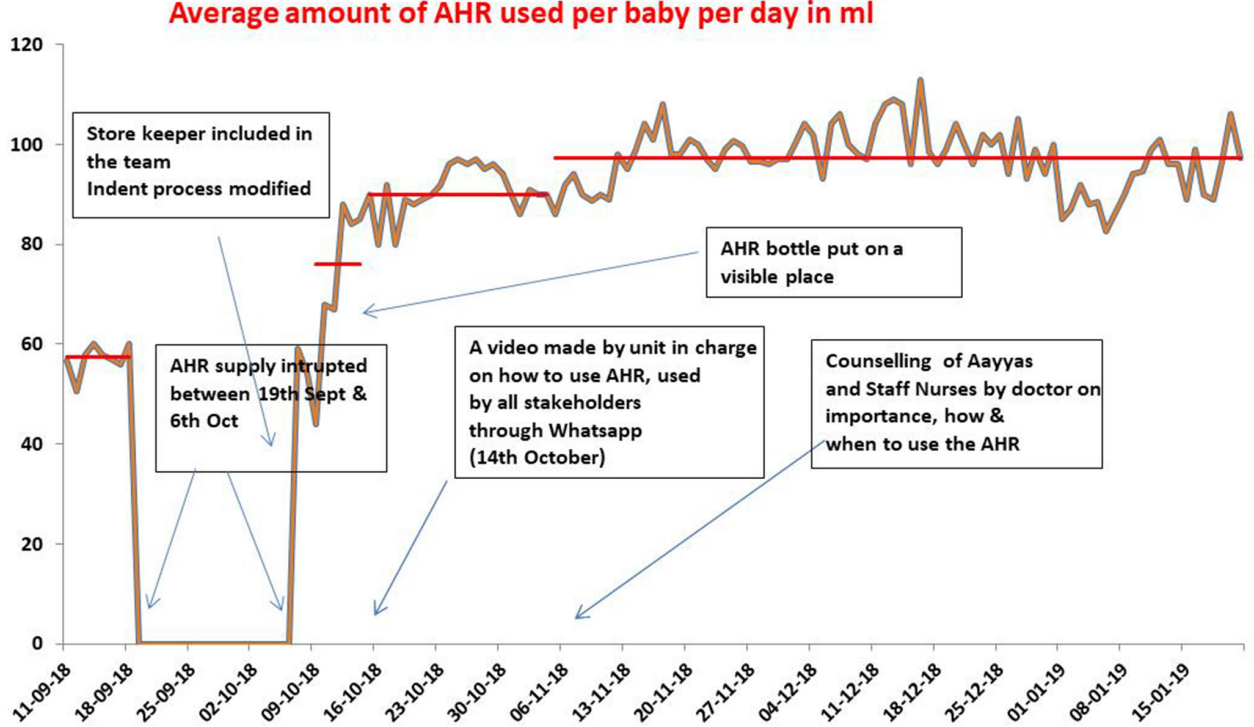

Figure 1 Average amount of AHR used per baby per day in $\mathrm{mL}$. AHR, alcoholic hand rub.

considerable improvement until we started to find out the specific reasons to low use of AHR and developed practical solutions to those reasons. We used the QI analytical tool, fishbone analysis. Successive tests using PDSA cycles helped us to refine the solutions until they were efficient and effective.

Initially, we faced some challenges due to QI methods being very new to the health providers and then difficulty in bringing people together and change their behaviour. We overcome these challenges by having weekly meeting and addressing people's concerns. We also developed a system using social media to share our concerns and to develop solutions to address them.
We did not have a system to collect all the relevant indicators to this work, so analysed the data which was being collected. Our goal was to improve hand hygiene; we also measured mortality. This QI project was not designed to assess whether the improvement in hand hygiene caused the reduction in mortality. Because many factors could lead to changes in mortality, we cannot say that it was due to this project. If we had collected monthly data on antibiotic use in the SNCU and this decreased as hand hygiene improved, we could have a better argument that the two were linked. But these data are not available. Regardless of our inability to establish a causal relationship between AHR use and mortality, we are reassured that both have improved.

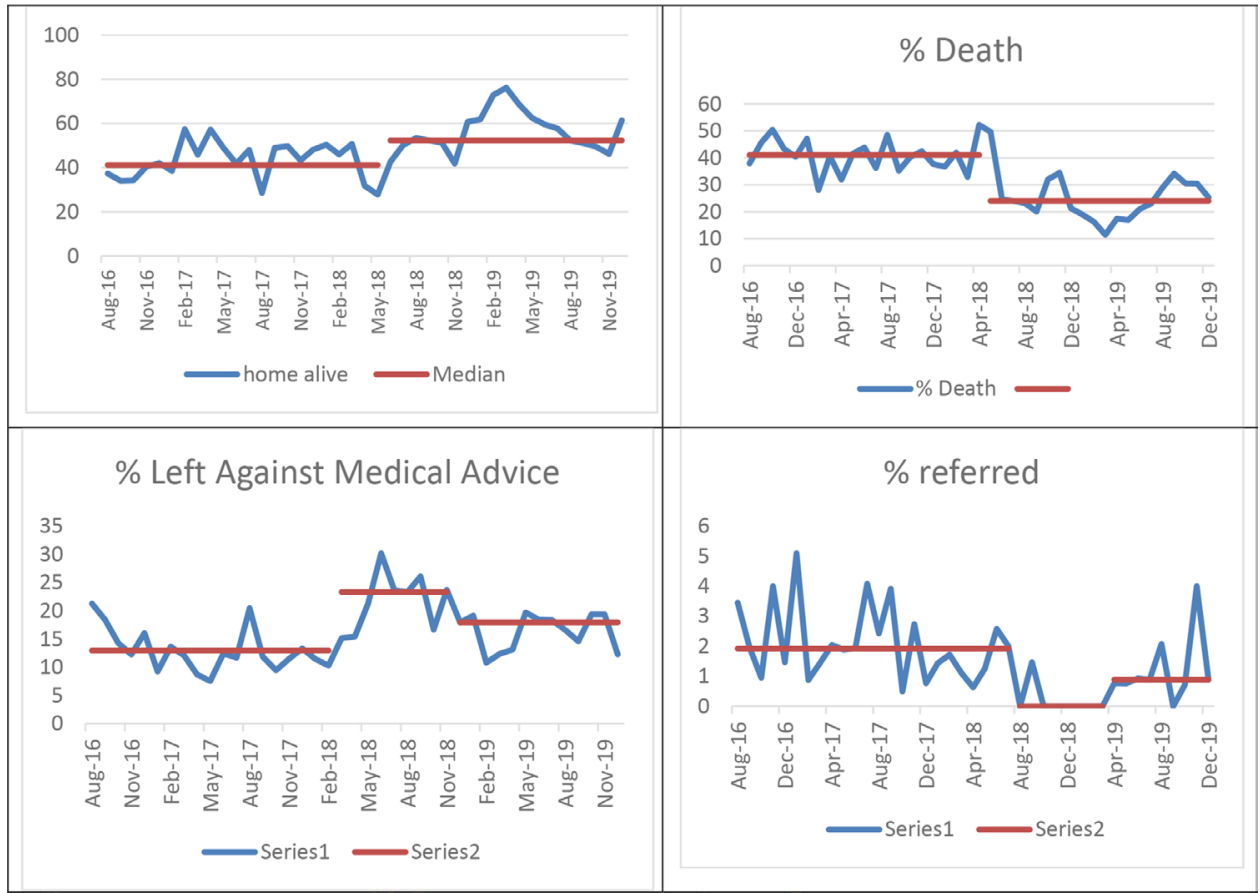

Figure 2 Comparison of \% deaths, \% LAMA, \% referred and discharged home alive. 
We believe that some of the learnings are not generalisable to other health settings while all others are likely to be replicable. For example, the optimum volume calculated per baby per day may be variable due to a number of times a baby would be touched but the method we calculated with can be very useful to all. We also strongly believe that the QI approaches, such as working in a team, looking for simple and practical solutions based on root cause analysis and testing and adapting different solutions are highly generalisable to other health settings in India and other LMICs.

\section{CONCLUSION}

The improper use of AHR is common in many health facilities in India and other LMICs. Healthcareassociated infections are a continuing problem in intensive care units, a serious source of morbidity, mortality and excess healthcare cost. ${ }^{14}$ Investigations of the transmission source of most healthcareassociated infections pointed to Health Care Worker hand-to-patient contact. ${ }^{15-17}$ Proper hand hygiene is the single most effective means of preventing the transfer of potential pathogens from staff to patient and from patient to patient. ${ }^{712}$ Multiple stakeholders are involved in providing healthcare in the system and have multiple level of involvement contributing toward hand hygiene. Also, there exist multiple factors which contribute toward low use of hand rub. QI methods particularly seem appropriate to solve such kind of complex problem. Involving all the stakeholders that is, doctors, staff nurses, ward aayas and parents and attendants, we were able to identify the factors, which were not allowing the proper use of AHR and address these factors.

This work substantially improved the use of hand hygiene practices in the SNCU at our hospital and mortality decreased at the same time. Because the majority of changes that we did were focused on making the system easier for staff and people to use AHR properly, we believe it will be sustainable.

We are also considering that this work could be easily adapted to other hospitals. The contextual factors in the SNCU may differ from one place to other, but QI approaches of forming a team, analysing and measuring the problem, developing and testing change ideas and then sustaining successful changes are replicable. In fact, the QI approaches are currently used extensively by different agencies supported by NQOCN and AIIMS, New Delhi, to improve various systems to provide better care. ${ }^{9}$ This is one strategy to improve processes in 'LaQshya', a flagship programme of Government of India for labour room and maternity operation theatre. ${ }^{18}$

Author affiliations

${ }^{1}$ Department of Quality Improvement, Nationwide Quality of Care Network, New Delhi, Delhi, India
${ }^{2}$ Department of Pediatrics, Netaji Subhash Chandra Bose Medical College and Hospital, Jabalpur, India

${ }^{3}$ Netaji Subhash Chandra Bose Medical College and Hospital, Jabalpur, India

${ }^{4}$ Nationwide Quality of Care Network, New Delhi, Delhi, India

${ }^{5}$ Department of Neonatology, Kalawati Saran Children's Hospital, New Delhi, Delhi, India

${ }^{6}$ Department of Neonatology, Lady Hardinge Medical College, New Delhi, Delhi, India ${ }^{7}$ Faculty of Medicine, University of Kuala Lumpur Royal College of Medicine Perak, Ipoh, Malaysia

${ }^{8}$ National Health Mission, Government of Madhya Pradesh, Bhopal, India

${ }^{9}$ - Independant Consultant, Nairobi, Kenia

Twitter Mahtab Singh @DrMahtabSingh1 and Nigel Livesley @NigelLivesley

Contributors MahtabSingh, AK were responsible for conducting onsite visits and mentoring/coaching of the quality improvement team at the facility. AA, DS, PKK and ManishSingh were responsible for conceptualising the project, collecting and collating data from the department and providing managerial and technical inputs to carry this work. MahtabSingh, AA, VK, RSS and NL were responsible for conceptualising the project, developing the draft manuscript and analysing the data from the facility. All listed authors have contributed significantly in conceptualising, designing the study, in its conduct, compilation, analysis and contributing to the manuscript. AA is responsible for the overall content as the guarantor.

Funding Unicef Madhya Pradesh state office funded quality improvement (QI) work in 10 specialised newborn care units (SNCUs) of the state through an agreement with National Health Mission, Government of Madhya Pradesh. National Health Mission, Government of Madhya Pradesh, sponsored lodging and boarding of Nationwide Quality Of Care Network coaches/mentors to carry QI work in 10 SNCUs across state through this agreement.

\section{Competing interests None declared.}

Patient and public involvement Patients and/or the public were not involved in the design, or conduct, or reporting, or dissemination plans of this research.

Patient consent for publication Not required.

Ethics approval As this was a quality improvement initiative to improve a process involved in hand hygiene practices, no ethical approval was required. Although the ethical committee of the Netaji Subhash Chandra Bose Medical College and Hospital was informed about this work in advance.

Provenance and peer review Not commissioned; externally peer reviewed.

Data availability statement Data are available upon request. All the relevant data to this QI work is available at a reasonable request.

Open access This is an open access article distributed in accordance with the Creative Commons Attribution Non Commercial (CC BY-NC 4.0) license, which permits others to distribute, remix, adapt, build upon this work non-commercially, and license their derivative works on different terms, provided the original work is properly cited, appropriate credit is given, any changes made indicated, and the use is non-commercial. See: http://creativecommons.org/licenses/by-nc/4.0/.

ORCID iD

Vikram Datta http://orcid.org/0000-0002-1047-6884

\section{REFERENCES}

1 NEONATAL SEPSIS IN NEONATAL INTENSIVE CARE UNIT: EVIDENCE STUDY Cecilia OlíviaParaguai de Oliveira1, Juliana Raquel Silva Souza1, Regimar Carla Machado2, Alexsandra Rodrigues Feijao2, Nilba Lima de Souza2.

2 Chakravarthy M, Adhikary R, Gokul B, et al. Hospital acquired infection is inversely related to utilization of isopropyl alcohol and tissue paper pulls--a prospective observational study. J Assoc Physicians India 2011;59:548-50.

3 You D, Jones G, Hill K, et al. Levels and trends in child mortality, 1990-2009. Lancet 2010;376:931-3.

4 Sustainable developmental goal3:National family health survey (NFHS) Data 2015-2016.

5 Zodpey S, Paul VK. PHFI, AlIMS, and SC-State of India's Newborns (SOIN) 2014-A Report, Public Health Foundation of India, All India Institute of Medical Sciences and Save the Children, New Delhi, India, 2016. Available: http://www.newbornwhocc. org/SOIN PRINTED\%2014-9-2014.pdf 
6 Boyce JM, Pittet D, Healthcare Infection Control Practices Advisory Committee, et al. Guideline for hand hygiene in health-care settings. recommendations of the healthcare infection control practices Advisory Committee and the HIPAC/SHEA/APIC/IDSA hand hygiene Task force. Am J Infect Control 2002;30:S1-46.

7 Helder OK, Brug J, Looman CWN, et al. The impact of an education program on hand hygiene compliance and nosocomial infection incidence in an urban neonatal intensive care unit: an intervention study with before and after comparison. Int J Nurs Stud 2010;47:1245-52.

8 Helder O, van den Hoogen A, de Boer C, et al. Effectiveness of non-pharmacological interventions for the prevention of bloodstream infections in infants admitted to a neonatal intensive care unit: a systematic review. Int J Nurs Stud 2013;50:819-31.

9 BMJ Quality improvement report Improving postpartum care in a large hospital in New Delhi, India Mona Chopra1, Neerja Arora2, Shailja Sinha3, Silvia Holschneider4, Nigel Livesley4.

10 Deorari A, Mehta R, Livesley N. Improving the quality of care for mothers and newborns in health facilities: point of care quality improvement. Coaching manual. New Delhi, India: World Health organization, regional office for south-east Asia, 2017. Available: http:// apps. who. int/ iris/ bitstream/ 10665/ 255876/ 1/ 9789290225485-eng. Pdf

11 Singh R, Singh M, Jha R. Improving quality in healthcare: a practical guide for health care providers. Technical report. published by the USAID assist project. Bethesda, MD: University research Co., LLC (URC). 2016. Available: https://www.usaidassist. org/resources/improving-quality-healthcare-practical-guide-healthcare-providers

12 Improving the quality of care for mothers and newborns in health facility. Available: https://www.newbornwhocc.org/POCQI-LearnerManual.pdf

13 Run charts revisited: a simulation study of run chart rules for detection of non-random variation in health care processes. Available: https://journals.plos.org/plosone/article?id=10.1371/ journal.pone.0113825

14 Nathens AB, Chu PT, Marshall JC. Nosocomial infection in the surgical intensive care unit. Infect Dis Clin North Am 1992;6:657-75.

15 Becks VE, Lorenzoni NM. Pseudomonas aeruginosa outbreak in a neonatal intensive care unit: a possible link to contaminated hand lotion. Am J Infect Control 1995:23:396-8.

16 Patterson JE, Vecchio J, Pantelick EL, et al. Association of contaminated gloves with transmission of Acinetobacter calcoaceticus var. anitratus in an intensive care unit. Am J Med 1991;91:479-83.

17 Bauer TM, Ofner E, Just HM, et al. An epidemiological study assessing the relative importance of airborne and direct contact transmission of microorganisms in a medical intensive care unit. $J$ Hosp Infect 1990;15:301-9.

18 Labour room quality improvement intitative, 2018. Available: https:// nhm.gov.in/New_Updates_2018/NHM_Components/RMNCH_MH_ Guidelines/LaQshya-Guidelines.pdf 